\title{
Magnetic alteration of zero-age oceanic basalt
}

\author{
Dennis V. Kent Lamont-Doherty Earth Observatory, Palisades, New York 10964 \\ Jeff Gee Scripps Institution of Oceanography, La Jolla, California 92093
}

\begin{abstract}
The youngest sampled submarine lava flow, which erupted June 1993 on the Juan de Fuca Ridge, provides the basis for a tight constraint on the initial or zero-age magnetization state of MORB. Detailed profiles of magnetic hysteresis parameters, Curie temperatures, and unblocking temperatures of NRM with respect to the chilled margin of a pillow fragment show evidence of significant oxidation, which preferentially affected the finest grain-size fraction and principal remanence carrier of the titanomagnetite magnetic mineralogy. The oxidation must have occurred during or immediately after initial cooling, implying that MORB is already appreciably magnetically altered before aging. Nevertheless, successful results of Thellier paleointensity experiments on the basalt sample lend support to the idea that crustal magnetization represented by MORB preserves a record of geomagnetic intensity variations that may be reflected in small-scale magnetic anomalies.
\end{abstract}

\section{INTRODUCTION}

Remanent magnetization of mid-ocean ridge basalt (MORB) is the primary source for marine magnetic anomalies (Smith, 1990). The remanent magnetization acquired upon initial emplacement and cooling of MORB at the ridge axis, however, is eventually altered, resulting in a decrease in remanent intensity, an increase in Curie temperature, and associated changes in other magnetic properties (e.g., Irving, 1970). Estimates of the effective time constant of the magnetic alteration have ranged as high as $500 \mathrm{k} . \mathrm{y}$. (Johnson and Atwater, 1977). More recent analyses of MORB samples and magnetic anomaly profiles from a fast-spreading ridge system suggest that the time constant is much shorter, on the order of $20 \mathrm{k} . \mathrm{y}$. or less (Gee and Kent, 1994). The short time constant of magnetization change emphasizes the need to establish the true initial or zero-age magnetization state of MORB to constrain alteration models.

In June 1993, acoustic detection of a sea-floor spreading episode on the Juan de Fuca Ridge (Fox and Radford, 1995) was followed within a month by observations and sampling by submersible of a fresh lava flow about $2.5 \mathrm{~km}$ long, $300 \mathrm{~m}$ wide, and up to $30 \mathrm{~m}$ thick (Embley et al., 1995). Johnson and Tivey (1995) reported natural remanent magnetization (NRM) values from four samples of the New Flow. Our sample of this zero-age lava flow was obtained by submersible (TURTLE dive 787-20-94; September 1994) at $46^{\circ} 31.48^{\prime} \mathrm{N}, 129^{\circ} 34.63^{\prime} \mathrm{W}$; a large fragment, labeled R-1, of what was described as a collapsed pillow was provided to us by H. P. Johnson (University of Washington). The sample was $\sim 25 \mathrm{~cm}$ long, $10 \mathrm{~cm}$ wide, and about $12 \mathrm{~cm}$ in depth from an outer glassy margin. The glassy margin was rounded and resembled the quenched exterior of a pillow, although very little glass was preserved intact; the interior of the pillow was a dark, apparently fresh, fine-grained basalt with a vesicular rind on the inner surface. We cut a $1-\mathrm{cm}$-thick slab perpendicular to the glassy margin, then subdivided the slab into several parallel columns of specimens about $1 \mathrm{~cm}$ on a side, specimens $a$ to $k$ representing successively greater distance from the upper glassy margin to just above the lower vesicular rind. Specimens from one column were crushed for hysteresis and Curie temperature measurements on $\sim 25 \mathrm{mg}$ chips; internally oriented specimens from other columns were used for characterizing the NRM by thermal and alternating field (AF) demagnetization as well as modified Thellier paleointensity experiments.

\section{MAGNETIC PROPERTIES}

Variations in grain size and concentration of magnetic minerals are expected as a function of cooling rate or distance from the rapidly quenched, glassy margin (Marshall and Cox, 1971; Ryall and Ade-Hall, 1975) and are reflected in magnetic hysteresis properties. Coercivity $\left(B_{c}\right)$ and remanent coercivity $\left(B_{c r}\right)$ decrease from high values $(\sim 100 \mathrm{mT})$ nearest the glassy margin (specimen $a)$ to below $10 \mathrm{mT}$ in specimen $k$ (Fig. 1). The ratio of saturation remanence, $M_{r s}$, to saturation magnetization, $M_{s}$, is 0.5 to 0.6 near the glassy margin (specimens $a$ to $c$ ), indicative of a very fine grained magnetic mineralogy. Magnetic carriers in MORB have a dominant cubic anisotropy (Gee and Kent, 1995), which has a theoretical $M_{r s} / M_{s}$ limit of 0.83 or 0.87 for a uniform single domain population of grains (Joffe and Heuberger, 1974). The progressive decrease in $M_{r s} / M_{s}$ with depth (specimens $c$ to $k$ ) most likely corresponds to a coarsening in overall magnetic grain size, whereas the off-trend hysteresis ratios and very high coercivities in the outermost part of the sample (specimens $a$ to $c$ ) may reflect a contribution of ultrafine (superparamagnetic) grains.

NRM intensity shows a large increase from the glassy margin, followed by a gradual reduction with peak values in specimens $b$ and $c$, whereas the depth profiles of $M_{r s}, M_{s}$, and magnetic susceptibility show generally increasing values with depth (Fig. 2A). A similar pattern of NRM intensity variation was predicted by Marshall and Cox (1971) for moderate-size MORB pillows or flows where the cooling rate can result in a localized optimum for remanence acquisition in terms of fine grain size and concentration of the carrier. The peak NRM intensity (converted to volumetric units) is $54 \mathrm{~A} / \mathrm{m}$, within the range of uncertainty of the mean value of $67.1 \pm 15.8 \mathrm{~A} / \mathrm{m}$ (standard deviation) reported by Johnson and Tivey (1995) for four separate rock samples (11 specimens) from the New Flow.

Curie temperature decreases with depth in the pillow, from above $200{ }^{\circ} \mathrm{C}$ near the margin to about $120{ }^{\circ} \mathrm{C}$ in the interior (Fig. 2B). A Curie temperature of $120^{\circ} \mathrm{C}$ would be compatible with a nominal titanomagnetite composition near $\mathrm{Fe}_{2.3} \mathrm{Al}_{0.1} \mathrm{Ti}_{0.6} \mathrm{O}_{4}$ (ATM60) typical for MORB (Özdemir and Moskowitz, 1992; O'Reilly, 1984). However, the higher Curie temperatures near the quenched pillow margin imply that either the effective ulvöspinel content of a stoichiometric titanomagnetite is considerably lower $(\sim$ ATM 45$)$ or the degree of nonstoichiometry due to oxidation of a uniform ATM60 composition is already appreciable. High-temperature nonstoichiometry may result in significant variation in $\mathrm{Cu}$ rie temperature for TM60 of up to $\sim 85^{\circ} \mathrm{C}$ within the single-phase stability field (Hauptman, 1974; Senderov et al., 1993; Wanamaker and Moskowitz, 1994). This was thought to be the likely mechanism responsible for the radial variation in bulk Curie temperatures in young MORB pillows (Grommé et al., 1979). However, MORB glasses are significantly more reduced than the corresponding pillow interiors (Christie et al., 1986). If the ATM60 grains stayed in equilibrium with the oxygen fugacity, the resulting high-temperature nonstoichiometry would be expected to produce an increase in $\mathrm{Cu}$ rie temperatures with depth in the pillow, opposite to what is observed in the New Flow sample and in other young MORB pillow fragments (e.g., Grommé et al., 1979). Although we cannot exclude the possibility of an original variation in titanomagnetite composition (maximum grain size $\sim 5 \mu \mathrm{m}$ within $5 \mathrm{~cm}$ of chilled margin and therefore difficult to microprobe), an alternative explanation for the 
Figure 1. Bilogorithmic plot of hysteresis parameters coercivity and remanent coercivity $\left(B_{c}\right.$ and $\left.B_{c r}\right)$ against saturation remanence/saturation magnetization $\left(M_{r s} / M_{s}\right)$ as measured on Princeton Measurements alternating gradient force magnetometer $(-1$ to $+1 \mathrm{~T})$ and corrected for high-field $(0.7-$ 1.0 T) slope for specimens from transect through New Flow basalt sample R-1. Data points are connected

in sequence from specimen a $(0.5 \mathrm{~cm}$ from chilled margin) to specimen $k(9.2 \mathrm{~cm}$ from chilled margin). Inset: Same data as bilogorithmic plot, following Day et al. (1977), of $M_{r s} / M_{s}$ against $B_{c r} / B_{c}$; star is theoretical locus for single-domain end member with triaxial cubic anisotropy (Joffe and Heuberger, 1974).

depth variation in Curie temperature in the New Flow is variable degrees of low-temperature oxidation that occurred in the final stages of cooling and shortly (a few years) thereafter.

The peak in NRM intensity that occurs just below the glassy margin is thus not only associated with the local maximum in the $M_{r s} / M_{s}$ ratio, signifying the highest relative concentration of a stable single-domain magnetic carrier, but also with high Curie temperatures, signifying that this fraction is the most uniformly and highly oxidized. Evidently, the inherent grain-size dependence of magnetization capacity (Dunlop, 1981) is more potent than the reduction of magnetization associated with oxidation (Marshall and Cox, 1972; O'Reilly, 1984) in the resulting magnetization profile through the pillow.

\section{DEMAGNETIZATION OF NRM}

Another signature of magnetic alteration in young pillow basalt is that a significant fraction of NRM unblocking tends to occur above the dominant bulk Curie point determined in high-field thermomagnetic experiments (Kent and Gee, 1994). This phenomenon occurs in the New Flow sample (Fig. 3). The median demagnetization temperature of NRM decreases from around $200{ }^{\circ} \mathrm{C}$ in the outer parts to around $170{ }^{\circ} \mathrm{C}$ in the interior of the pillow basalt sample (Fig. 2B). More than half of NRM unblocking thus tends to occur above the dominant Curie points, with the notable exception of the specimens closest to the pillow margin in which the high-field Curie points are elevated and more compatible with the NRM unblocking temperatures.

The observed relationship between NRM unblocking and highfield thermomagnetic behavior can be explained by grain-size-dependent alteration (Bina and Prévot, 1989; Kent and Gee, 1994), wherein abundant fine-grained and preferentially oxidized ATM60 carries most of the NRM, whereas a small population of coarser and less-oxidized grains of ATM60 accounts for most of the high-field magnetic properties. Only near the quenched margin of the pillow, where the ATM60 is represented mainly by very fine grains that are likely to be more uniformly and thoroughly oxidized, do the carriers of the NRM and high-field magnetizations more nearly correspond. The Curie temperature of $237^{\circ} \mathrm{C}$ that was reported by Johnson and Tivey (1995) from a low-field thermomagnetic curve from the interior ( $>2 \mathrm{~cm}$ from the chilled margin) of a New Flow sample is appreciably higher than obtained from our high-field determinations (Fig. 3). Their low field $(0.15 \mathrm{mT})$ thermomagnetic curve is effectively a continuous thermal demagnetization of NRM, incorporating the temperature dependence of $M_{s}$. Therefore, the difference between the low- and high-field thermomagnetic results fur-
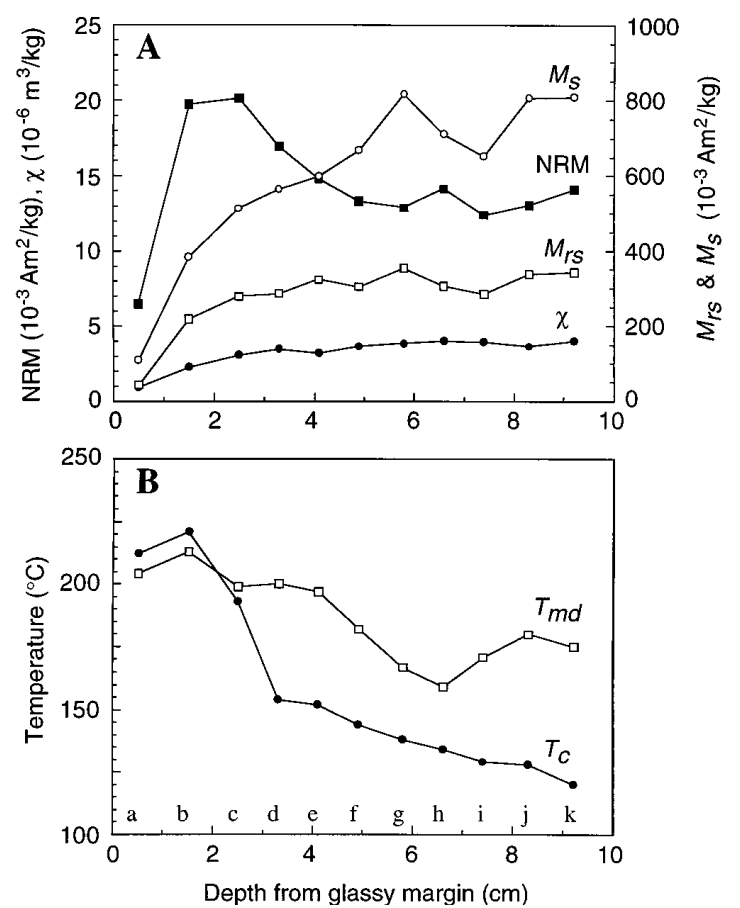

Figure 2. Variation of magnetic parameters with depth from glassy outer margin (specimens a to $k$ ) in New Flow basalt sample R-1. A: $\boldsymbol{M}_{\boldsymbol{s}}$, $M_{r s}$, magnetic susceptibility $(\chi)$, and NRM intensity as vector sum of thermal demagnetization intervals to account for multicomponents. $B$ : Curie temperature $\left(T_{c}\right)$ estimated from high-field thermomagnetic curves obtained on Alpha Precision translation balance $\left(0.15 \mathrm{~T}, 50{ }^{\circ} \mathrm{C} /\right.$ min heating in air); median demagnetization temperature $\left(T_{m d}\right)$ of NRM calculated from vector sum of demagnetization intervals.

ther emphasizes that the remanence is controlled by phases not well represented in high-field bulk measurements.

A fortuitous circumstance allows us to further evaluate the timing of remanence acquisition in the New Flow basalt sample. The NRM of specimens nearest the glassy margin shows essentially univectorial decay with progressive thermal demagnetization and has a steep downward inclination with respect to the upper cooling margin (Fig. 4A). By specimens $c$ and $d$, however, an additional magnetization component appears over the lower part of the unblocking temperature spectrum. This overprint with a relatively shallow direction becomes progressively more dominant in relative magnitude as its maximum unblocking temperature increases to about $200^{\circ} \mathrm{C}$ with depth in the pillow, even though the characteristic magnetization is still clearly present over higher unblocking temperatures. In contrast, $\mathrm{AF}$ demagnetization trajectories are virtually univectorial to $90 \mathrm{mT}$ for all specimens (Fig. 4B), and hence this technique is not able to resolve the two components that evidently have overlapping coercivities but distinct unblocking temperatures.

The high maximum unblocking temperatures of the characteristic magnetization throughout the sample point to alteration during the initial cooling of the basalt. The overprint component has a lower unblocking temperature and a direction about $115^{\circ}$ away from that of the characteristic component, and can hardly be attributed to secular variation of the field, but more plausibly reflects acquisition after physical rotation of the basalt fragment during drainback and collapse of the upper pillowed crust of the New Flow. The outer margin of the pillow was probably already cooled close to ambient temperature, resulting in the preservation of a univectorial NRM, whereas the interior of the sample may still have been at modest temperatures or may have been moderately reheated after physical rotation to account for the acquisition of the overprint magnetization. 
Figure 3. Comparison of high-field thermomagnetic $\left(M_{s}\right)$ and NRM unblocking temperature curves for specimen $d$ at depth of $3.3 \mathrm{~cm}$ below chilled margin of New Flow basalt sample R-1. Curie temperature estimated from high-field $(0.15 \mathrm{~T})$ thermomagnetic heating curve is shown by open arrow; Curie temperature estimated from a low-field $(0.15 \mathrm{mT})$ thermomagnetic heating curve from interior of another sample of New Flow material reported by Johnson and Tivey (1995) is shown by filled arrow.

\section{PALEOINTENSITY}

Paleointensity data from modified Thellier double-heating experiments on specimens from the New Flow indicate that despite evidence of alteration, the resulting magnetizations can preserve a reliable record of the geomagnetic field. Only the outermost specimens in the New Flow sample exhibit univectorial magnetizations over the dominant unblocking temperature range that are a prerequisite for meaningful Thellier analyses. These specimens yield internally consistent data to $325^{\circ} \mathrm{C}$ (Fig. 5), well above the bulk Curie temperatures of the samples, with quality factors (Coe et al., 1978 ) from 19.5 to 44.6 that exceed the threshold of about 10 suggested by Grommé et al. (1979) for reliable paleointensity determinations (Table 1). More important, the weighted mean paleofield estimate of $0.0528 \pm 0.0122 \mathrm{mT}$ (standard error) is remarkably close to the geomagnetic field magnitude $(0.0537 \mathrm{mT})$ for the New Flow site.

\section{DISCUSSION}

The coincidence of the peak in NRM intensity and the reliable paleointensity determinations made on the most highly oxidized, outermost part of the New Flow sample suggests that at least the finest-grained basalts provide a strong, faithful record of the paleofield. Reliable paleointensity determinations have been difficult to obtain from MORB (e.g., Dunlop and Hale, 1976), although successful results of Thellier experiments (original or modified method) were reported by Grommé et al. (1979) from a number of young $(<0.7 \mathrm{Ma})$ pillow fragments, as well as by Pick and Tauxe (1993a, 1993b) from MORB glasses of Holocene and Cretaceous age. The degree to which magnetizations of MORB more generally preserve a long-lasting record of the original paleofield strength thus remains to be determined, but the present results lend support to the idea that crustal magnetization represented by MORB potentially contains a high-resolution paleointensity signal that may be reflected in small-scale marine magnetic anomalies (Cande and Kent, 1992).

Unless the finest TM60 grains are increasingly out of equilibrium with oxygen fugacities during initial cooling, it is difficult to attribute the elevation of Curie and NRM unblocking temperatures near the chilled margin of the basalt to high-temperature oxidation. The observed change in Curie temperatures with depth in the pillow is opposite to the trend expected from high-temperature oxidation, because MORB pillows are initially more oxidized in their interiors (Christie et al., 1986). Furthermore, the observed magnitude of the increase in Curie temperature $\left(\sim 100^{\circ} \mathrm{C}\right)$ is more than double the maximum change expected from single-phase high-temperature oxidation $\left(25-45^{\circ} \mathrm{C}\right.$; Hauptman, 1974) at temperatures relevant for MORB lavas (1050-1200 ${ }^{\circ} \mathrm{C}$; Walker et al., 1979). This leaves lowtemperature oxidation, which may have been accelerated if it occurred at moderate temperature during initial cooling, as the likely
Figure 4. Vector endpoint diagrams of progressive (A) thermal and (B) AF demagnetization of NRM of specimens a to $k$ from adjacent columns through New Flow erence frame is in mean plane containing two magnetization components composing NRM. Filled circle near each specimen label is initial NRM vector end point; successive connected filled circles are vector end points in $\mathrm{A}$ at $25^{\circ} \mathrm{C}$ steps from $75{ }^{\circ} \mathrm{C}$ to $500^{\circ} \mathrm{C}$ with $150^{\circ} \mathrm{C}$ step indicated by open circle for reference, and in B at $5 \mathrm{mT}$ steps from $5 \mathrm{mT}$ to $90 \mathrm{mT}$ with $20 \mathrm{mT}$ step indicated by open circle for reference. basalt sample R-1. Ref-
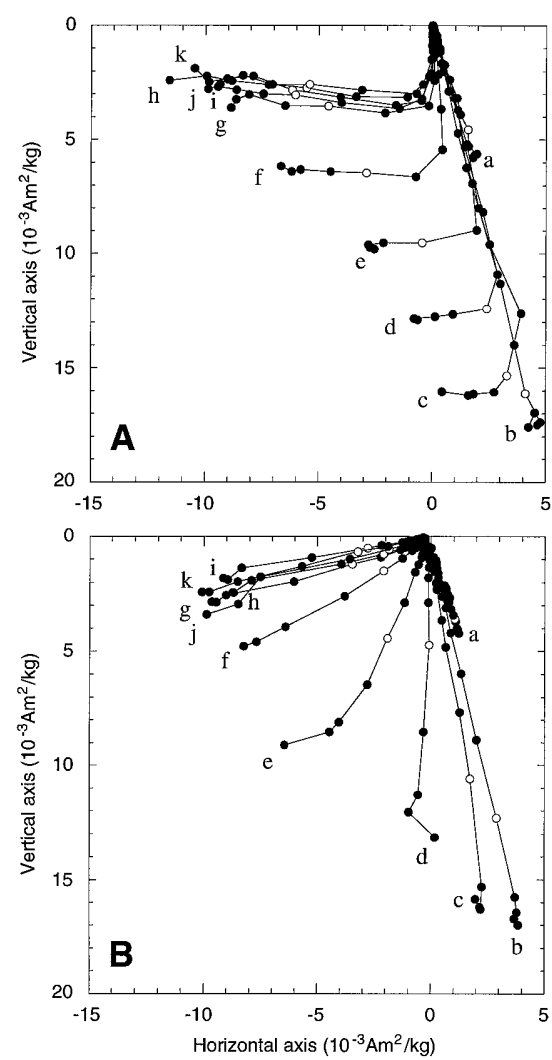

Figure 5. Example of results of modified Thellier (double heating) experiment, following procedures and analytical techniques described by Coe et al. (1978), for outermost specimen from New Flow sample R-1. Sample is heated twice in air to given temperature (shown in upper right) and cooled to room temperature, first in zero field, then in laboratory field of 0.0358 mT; pTRM (thermoremanent magnetization) backchecks (at temperatures shown in lower left) are connected to NRM remaining after prior heating temperature by line segments.

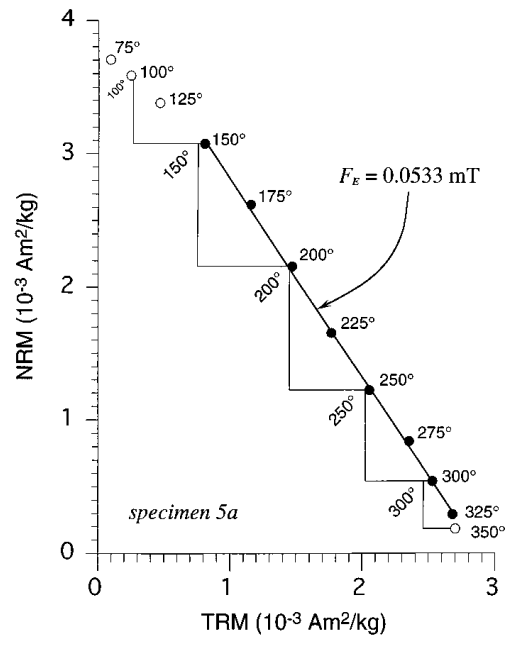

Filled circles are NRM-TRM points used for bivariate linear regression to estimate paleointensity, $F_{E}$, and to determine data assessment factors (Table 1). Field intensity at New Flow geographic location is $0.0537 \mathrm{mT}$.

mechanism responsible for the observed variation in magnetic properties in the New Flow basalt. If significant oxidation occurred at temperatures below the Curie point, the success of the Thellier paleointensity determinations implies that the resulting chemical remanence can closely mimic the properties of a thermoremanent magnetization (TRM). In this case, the loss in NRM due to oxidation may be proportional to the loss in TRM capacity, and therefore a successful Thellier paleointensity experiment may not be sufficiently diagnostic of TRM (e.g., Briden and McClelland, 1994).

Regardless of the temperature at which oxidation occurred, our results from the zero-age New Flow (and comparable results from axial lavas from the East Pacific Rise; e.g., Gee and Kent, 1994; Kent and Gee, 1994) suggest that MORBs become appreciably magnetically altered very early in their history. One implication of such 
TABLE 1. PALEOINTENSITY RESULTS FROM THELLIER DOUBLEHEATING EXPERIMENTS ON NEW FLOW BASALT SPECIMENS

\begin{tabular}{lrrrccccc}
\hline \hline Spec. & $n$ & $\Delta T\left({ }^{\circ} \mathrm{C}\right)$ & $f$ & $g$ & $\sigma_{\mathrm{b}} /|\mathrm{b}|$ & $q$ & MAD & $F_{E}(\mathrm{mT})$ \\
\hline $2 \mathrm{a}$ & 10 & $100-325$ & 0.853 & 0.864 & 0.0455 & 24.3 & 0.7 & 0.0538 \\
$2 \mathrm{~b}$ & 10 & $100-325$ & 0.853 & 0.845 & 0.0290 & 24.9 & 1.0 & 0.0558 \\
$5 \mathrm{a}$ & 8 & $150-325$ & 0.650 & 0.845 & 0.1236 & 44.6 & 0.7 & 0.0533 \\
6a & 8 & $150-325$ & 0.632 & 0.848 & 0.0239 & 22.5 & 0.9 & 0.0495 \\
6b & 7 & $175-325$ & 0.625 & 0.807 & 0.0259 & 19.5 & 0.9 & 0.0499 \\
\multicolumn{2}{l}{ Mean $(N=5)$} & & & & & & 0.0528 \\
\end{tabular}

Note: Spec. is specimen, $n$ is number of NRM-TRM points over temperature range $\Delta T$ constituting $f$, the fraction of total extrapolated NRM spanned by least squares line segment used to estimate paleointensity $(F E)$ of each specimen; $g$ is gap factor for points defining least squares line segment, $\sigma_{b} / \mathrm{bl}$ is relative standard deviation of slope of least squares line segment, and $q$ is overall quality factor of paleointensity estimate (all defined in Coe et al., 1978); MAD is maximum angular deviation from principal component analysis of NRM vectors over $\Delta T$. Mean, plus or minus standard error, is average of the 5 specimen paleointensity values weighted according to $\left(q / F_{E}\right)^{2}$.

early alteration relates to the origin of the significant reduction in the magnetization of the extrusive layer over short spatiotemporal scales. The reduction is required to reconcile the seismically inferred thinning of the extrusive layer on axis and the presence of a short-wavelength magnetic anomaly high (Gee and Kent, 1994). The much more rapid alteration indicated by analysis of the New Flow material suggests that either some additional process (e.g., geomagnetic intensity variations) contributes to the magnetization contrast leading to the central anomaly magnetic high, or that the interpretation of seismic layer $2 \mathrm{~A}$ as corresponding to the magnetic source layer may need to be reconsidered.

Paleomagnetic data from the New Flow sample raise the practical issue of resolution of magnetization components in oceanic basalts. Magnetization components with discrete unblocking temperatures but overlapping coercivity spectra such as those present in the New Flow sample have been noted in basaltic lavas from $\mathrm{La}$ Palma and the Troodos ophiolite (Gee et al., 1993a, 1993b; see also Dinares-Turell and McClelland, 1991, for an example of the opposite relationship in another rock type). Unfortunately, most paleomagnetic studies of MORB typically employed only AF demagnetization with a general lack of complementary thermal demagnetization data. It is therefore unclear whether unresolved multicomponent magnetizations are widespread phenomena in MORB, which would have potential implications for bias in paleolatitudinal and paleosecular variation data from DSDP-ODP basement sites.

\section{ACKNOWLEDGMENTS}

Supported by National Science Foundation, Marine Geology and Geophysics Program (grants OCE-94-16839 and OCE-95-03916). We thank Paul Johnson for providing a sample of New Flow basalt, and Johnson, Bruce Moskowitz, and Maurice Tivey for constructive reviews of the manuscript. Lamont-Doherty Earth Observatory contribution 5490

\section{REFERENCES CITED}

Bina, M. M., and Prévot, M., 1989, Thermomagnetic investigations of titanomagnetite in submarine basalts: Evidence for differential maghemitization: Physics of the Earth and Planetary Interiors, v. 54, p. 169-179.

Briden, J. C., and McClelland, E., 1994, Experimental demonstration of primary thermoremanence in igneous rocks: Eos (Transactions, American Geophysical Union), v. 75, p. 196.

Cande, S. C., and Kent, D. V., 1992, Ultrahigh resolution marine magnetic anomaly profiles: A record of continuous paleointensity variations?: Journal of Geophysical Research, v. 97, p. 15075-15083.

Christie, D. M., Carmichael, I. S. E., and Langmuir, C. H., 1986, Oxidation states of mid-ocean ridge basalt glasses: Earth and Planetary Science Letters, v. 79, p. 397-411.

Coe, R. S., Grommé, S., and Mankinen, E. A., 1978, Geomagnetic paleointensities from radiocarbon-dated lava flows on Hawaii and the question of the Pacific nondipole low: Journal of Geophysical Research, v. 83, p. 1740-1756.

Day, R., Fuller, M. D., and Schmidt, V. A., 1977, Hysteresis properties of titanomagnetites: Grain-size and compositional dependence: Physics of the Earth and Planetary Interiors, v. 13, p. 260-267.

Dinares-Turell, J., and McClelland, E., 1991, A cautionary tale for paleomagnetists: A spurious apparent single component remanence due to overlap of blockingtemperature spectra of two components: Geophysical Research Letters, v. 18, p. $1297-1300$.

Dunlop, D. J., 1981, The rock magnetism of fine particles: Physics of the Earth and Planetary Interiors, v. 26, p. 1-26.

Dunlop, D. J., and Hale, C. J., 1976, A determination of paleomagnetic field intensity using submarine basalts drilled near the Mid-Atlantic Ridge: Journal of Geophysical Research, v. 81, p. 4166-4172.

Embley, R. W., Chadwick, W. W. J., Jonasson, I., Butterfield, D. A., and Baker, E. T. 1995, Initial results of the rapid response to the 1993 CoAxial event: Relationships between hydrothermal and volcanic processes: Geophysical Research Letters, v. 22, p. 143-146.

Fox, C. G., and Radford, W. E., 1995, Acoustic detection of a seafloor spreading episode on the Juan de Fuca Ridge using military hydrophone arrays: Geophysical Research Letters, v. 22, p. 131-134.

Gee, J., and Kent, D. V., 1994, Variations in layer 2A thickness and the origin of the central anomaly magnetic high: Geophysical Research Letters, v. 21, p. 297-300.

Gee, J., and Kent, D. V., 1995, Magnetic hysteresis in young mid-ocean ridge basalts: Dominant cubic anisotropy?: Geophysical Research Letters, v. 22, p. 551-554.

Gee, J., Staudigel, H., Tauxe, L., Pick, T., and Gallet, Y., 1993a, Magnetization of the La Palma Seamount Series: Implications for seamount paleopoles: Journal of Geophysical Research, v. 98, p. 11743-11767.

Gee, J., Varga, R., Gallet, Y., and Staudigel, H., 1993b, Reversed-polarity overprint in dikes from the Troodos ophiolite: Implications for the timing of alteration and extension: Geology, v. 21, p. 849-852.

Grommé, S., Mankinen, E. A., Marshall, M., and Coe, R. S., 1979, Geomagnetic paleointensities by the Thelliers' method from submarine pillow basalts: Effects of seafloor weathering: Journal of Geophysical Research, v. 84, p. 3553-3575.

Hauptman, Z., 1974, High temperature oxidation, range of non-stoichiometry and Curie point variation of cation deficient titanomagnetite $\mathrm{Fe}_{2.4} \mathrm{Ti}_{0.6} \mathrm{O}_{4+\gamma}$ : Royal Astronomical Society Geophysical Journal, v. 38, p. 29-47.

Irving, E., 1970, The Mid-Atlantic Ridge at $45^{\circ} \mathrm{N}$. XIV. Oxidation and magnetic properties of basalt; review and discussion: Canadian Journal of Earth Sciences, v. 7, p. 1528-1538.

Joffe, I., and Heuberger, R., 1974, Hysteresis properties of distributions of cubic single-domain ferromagnetic particles: Philosophical Magazine, v. 29, p. $1051-1059$.

Johnson, H. P., and Atwater, T., 1977, Magnetic study of basalts from the MidAtlantic Ridge, lat $37^{\circ} \mathrm{N}$ : Geological Society of America Bulletin, v. 88, p. $637-647$.

Johnson, H. P., and Tivey, M. A., 1995, Magnetic properties of zero-age oceanic crust; a new submarine lava flow on the Juan de Fuca Ridge: Geophysical Research Letters, v. 22, p. 175-178.

Kent, D. V., and Gee, J., 1994, Grain size-dependent alteration and the magnetization of oceanic basalts: Science, v. 265, p. 1561-1563.

Marshall, M., and Cox, A., 1971, Magnetism of pillow basalts and their petrology: Geological Society of America Bulletin, v. 82, p. 537-552.

Marshall, M., and Cox, A., 1972, Magnetic changes in pillow basalt due to sea-floor weathering: Journal of Geophysical Research, v. 77, p. 6459-6469.

O'Reilly, W., 1984, Rock and mineral magnetism: New York, Chapman and Hall, p. 220.

Özdemir, O., and Moskowitz, B. M., 1992, Magnetostriction in aluminum-substituted titanomagnetites: Geophysical Research Letters, v. 19, p. 2361-2364.

Pick, T., and Tauxe, L., 1993a, Holocene paleointensities: Thellier experiments on submarine basaltic glass from the East Pacific Rise: Journal of Geophysical Research, v. 98, p. 17949-17964.

Pick, T., and Tauxe, L., 1993b, Geomagnetic paleointensities during the Cretaceous normal superchron measured using submarine basaltic glass: Nature, v. 366, p. 238-242.

Ryall, P. J., and Ade-Hall, J. M., 1975, Radial variation of magnetic properties in submarine pillow basalt: Canadian Journal of Earth Sciences, v. 12, p. 1959-1969.

Senderov, E., Dogan, A. U., and Navrotsky, A., 1993, Nonstoichiometry of magnetite-ulvö spinel solid solutions quenched from $1200{ }^{\circ} \mathrm{C}$ : American Mineralogist, v. 78, p. 565-573.

Smith, G. M., 1990, The magnetic structure of the marine basement: Reviews in Aquatic Sciences, v. 2, p. 205-227.

Walker, D., Shibata, T., and DeLong, S. E., 1979, Abyssal tholeiites from the Oceanographer fracture zone: Contributions to Mineralogy and Petrology, v. 70, p. $111-125$.

Wanamaker, B. J., and Moskowitz, B. M., 1994, Effect of nonstoichiometry on the magnetic and electrical properties of synthetic single crystal $\mathrm{Fe}_{2.4} \mathrm{Ti}_{0.6} \mathrm{O}_{4}$ : Geophysical Research Letters, v. 21, p. 983-986.

Manuscript received December 29, 1995

Revised manuscript received April 17, 1996

Manuscript accepted May 1, 1996 